${ }^{1}$ Northwest Institute of Plateau Biology, China Academy of Sciences, Xining, P.R.China)

${ }^{2}$ Qinghai Academy of Animal and Veterinary Sciences, Xining, P.R.China

XIAO-LIN LUO ${ }^{1,2 *}$, JINGTAO XU², QUAN LI², YAPING WEI ${ }^{2}$ and XIN-QUAN ZHAO ${ }^{1}$

\title{
Growth and milk performance of yak in southern Qinghai area
} (short communication)

\begin{abstract}
The Study carried out in Xueshan Township, Guoluo prefecture, Qinghai Province, P. R. China from 1997 to 1999 on 1) Growth regulation of yak from born to adult and 1/4 wild yak from born to one and half year; 2) The effect of nursing or not on the growth and development of dam; 3) Meat performance of local yak; 4)Milk productivity of female yak. It can be served as the theory basis from which crossbreed improvement of yak and government decision could be drawn.
\end{abstract}

Key Words: Yak, domestic Yak, wild blood Yak, crossbreed, growth, milk performance, V.R.China

\section{Zusammenfassung}

Titel des Beitrages: Wachstums- und Milchleistungen des Yak im südlichen Quinghaigebiet Chinas (Kurzmitteilung)

Die Untersuchungen erfolgten in der Präfektur Guoluo des Verwaltungsbezirkes Xueshan der Provinz Quinghai der Volksrepublik China. Erfasst wurde das Wachstum der lokalen domestizierten Yaks von der Geburt bis zum ausgewachsenen Tier sowie das von Kreuzungstieren mit Wild Yaks (1/ 4 Wild Yak) von der Geburt bis zum Ende des ersten Halbjahres. Ferner wurde der Einfluss des Kälbersaugens auf das Wachstum und die Entwicklung der Mütter, die Fleischleistung der lokalen Yaks und die Milchleistung der weiblichen Yaks untersucht. Die Studie soll als theoretische Basis von Zuchtplanungen für Leistungsverbesserungen durch Kreuzungszucht beim Yak genutzt werden.

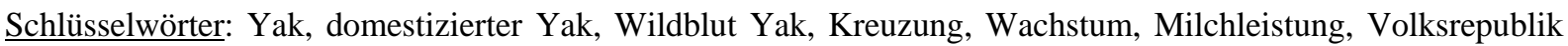
China

\section{Introduction}

Yaks are mainly distributed on the Qinghai Tibetan Plateau, in what is called the "nonpollution district," in an area with an altitude of above 3,000 meters. China has a total of 13,279,500 yaks, accounting for 92 percent of all the world's yaks, with a yearly meat yield of 300,000 tonne. They are mainly distributed in Qinghai, Tibet, Sichuan, Gansu, Xinjiang and Yunnan Province, with a distribution area of 3 million square kilometers. Qinghai, located between $31^{\circ} 39^{\prime}$ and $39^{\circ} 19^{\prime} \mathrm{N}$ and between $89^{\circ} 35^{\prime}$ and $103^{\circ} 04^{\prime} \mathrm{E}$, covers an area of $722,000 \mathrm{sq} \mathrm{km}$ and is $1,200 \mathrm{~km}$ from east to west and 800 $\mathrm{km}$ from north to south. It is one of the large pastoral areas in China. Qinghai has 4,786,900 yaks, accounting for 36 percent of all of China's yaks (CAI LIet al., 2003). The yak is a multi-purpose animal, providing its owners with milk (and the resultant milk products), meat, hair and wool, hide, work as a draught animal (packing, riding, ploughing) and faces-important as fuel in the absence of trees, but also as manure and as a building material. The harsh but varied environment greatly affects the performance of animals and output of the various products. There are also differences among types and breeds of yak, through these differences are usually confounded with 
differences among the areas where these types and breeds are located. In the 1990s, there was intensive use in Qinghai of wild yak semen by A.I., or the use of semi-wild yak bulls with natural mating, to try to improve the domestic yak productivity and "rejuvenate" the yak population. Some comparable data from observations of the $F_{1}$ (half wild yak blood), $\mathrm{B}_{1}$ (one quarter wild yak blood) and local yak under the same feeding management system in southern Qinghai (YAN SHOUDONG, 2002). It was found that the body measurements and weights of the semi- $\left(\mathrm{F}_{1}\right)$ and quarter-wild yak $\left(\mathrm{B}_{1}\right)$ were higher than those of domestic yak within the same age. The birth weight, height, length and heart girth of $F_{1}$ were greater than of the domestic yak calves and particularly at 18 months old, the measurements of both the $F_{1}$ and the $B_{1}$ were greater than of domestic yak. The economic benefit was great for the average production performance was increased by 20\% in offspring (LUO XIAOLIN, 2001).

The south part of Qinghai is a mainly yak raising area. Yak is an indispensable means of production and livelihood for local Tibetan people. During the last two decades, although the government have increased financial support for the construction of animal husbandry infrastructure in this area, especially for the grassland construction which is called the "four countermeasures" (fence, watering place for herdsman and animals, sedentary grazing, grass planting on pen), but the practical productivity of yak still tended to degradation owing to the degradation of natural grassland, overgrazing and degradation of yak breed for lack of systematical selection and breeding. The aim of this project was to estimate the growth and development, milking and meat productivity of yak including the wild blood yak, in order to give an evaluation for local yak and try to provide scientific basis for the policy maker.

\section{Materials and methods}

The body weight for domestic yak was determined at the age of newborn, 0.5,1,1.5,2,2.5,3,3.5,4,4.5,5 year old in May and October by using the electron balance with a number of each group more than 30 yaks from six households in Xueshan township, Maqing county, Guoluo prefecture. The 1/2 wild yak bulls were selected from Datong Yak Farm and distributed to same township as the herd bull mated naturally with local yak cow for producing $1 / 4$ wild yak, the originally yak bulls were castrated or sold out. The body weight of offspring( $1 / 4$ wild yak) was determined at the age of newborn, 0.5,1,1.5 in May and October by using the electron balance with a number of each group more than 30 yaks from three households in Xueshan township. 7 nursing yak and 5 non-nursing yak were selected to determine the bodyweight on the 10 May,1997, 7 November,1997, 15 March,1998, 7 June,1998 for detecting the calving or not on influence of the body condition of dam.

3 over 10 years old and 3 5-7 years old draft yak were grazed naturally no supplementary feeding with a medium body condition were selected randomly from the Xueshan township, stop grazing only supply water for 50 hours before slaughtered in October,1998 for the test of meat productivity including eye muscle area.

5 multiparous yak and 5 primiparous yak with a medium body condition from same households were selected to determine the milking productivity from May to September, the milking productivity was detected on three successive days at each month and milked one time in May and September, but milked twice in other months. For twice milking cow, milking time are 5-5:30am and 4-4:30 pm , the one time milking time is 5:00-6:00am, calves grazed with their dams and suckle them at the 
other time (except at night).

All data mentioned above were tested with t-test method.

Results

The results showed that the body weight of local yak aged from birth to 5 years old were measured at an interval of 6 months, a rapid growth before 2.5 years old and then a flat curve until 4 years old. From 4 years old on, the body weight varied with seasons (Table 1). However, the average body weight obtained from this study was lower than the previous investigation in early 80's in this area, which indicated a degeneration of the local yak genetics. The body weight of local yak from newborn to 5 years was $11.74 \pm 1.27 \mathrm{~kg} ; \quad 50.18 \pm 10.74 \mathrm{~kg} ; \quad 83.01 \pm 12.89 \mathrm{~kg} ; 99.42 \pm 16.31 \mathrm{~kg} ; 109.68 \pm 16.63 \mathrm{~kg}$; $134.10 \pm 7.77 \mathrm{~kg} ; 135.23 \pm 18.59 \mathrm{~kg} ; 141.31 \pm 40.71 \mathrm{~kg} ; 143.89 \pm 25.74 \mathrm{~kg} ; 196.68 \pm 21.27 \mathrm{~kg}$; $156.42 \pm 30.33 \mathrm{~kg}$ (Table 1).

Table 1

Comparison of body weight for 1/4 wild yak and yak (kg) (Vergleich der Körpergewichte von domestizierten Yaks und 1/ 4 Wild Yak Kreuzungstieren (kg))

\begin{tabular}{|c|c|c|c|c|c|}
\hline \multirow[t]{2}{*}{ Age } & \multicolumn{2}{|c|}{ Domestic yak } & \multicolumn{2}{|r|}{ 1/4 wild yak } & \multirow[t]{2}{*}{ increased } \\
\hline & $\mathrm{n}$ & $\mathrm{X} \pm \mathrm{s}$ & $\mathrm{n}$ & $\mathrm{X} \pm \mathrm{S}$ & \\
\hline newborn & 40 & $11.74 \pm 1.27$ & 30 & $12.94 \pm 2.24$ & 1.2 \\
\hline 6months & 30 & $50.18 \pm 5.26$ & 30 & $59.64 \pm 10.08$ & $9.46^{*}$ \\
\hline 1year & 30 & $83.01 \pm 8.45$ & 30 & $95.54 \pm 9.48$ & $12.53^{* *}$ \\
\hline 1.5 year & 30 & $99.42 \pm 15.65$ & 30 & $111.07 \pm 7.56$ & $11.65^{*}$ \\
\hline 2 year & 30 & $109.68 \pm 16.63$ & & & \\
\hline 2.5year & 30 & $134.10 \pm 7.77$ & & & \\
\hline 3 year & 30 & $135.23 \pm 18.59$ & & & \\
\hline 3.5 year & 30 & $141.31 \pm 40.71$ & & & \\
\hline 4 year & 30 & $143.89 \pm 25.74$ & & & \\
\hline 4.5 year & 30 & $196.68 \pm 21.27$ & & & \\
\hline 5 year & 30 & $156.42 \pm 30.33$ & & & \\
\hline
\end{tabular}

The Table 1 also showed that the comparison of body weight for yak and 1/4 wild yak under the same rearing system. The mean bodyweight of $1 / 4$ wild yak at newborn, 0.5 , $1,1.5$ years old were $12.94 \pm 2.24 \mathrm{~kg}, 59.64 \pm 7.55 \mathrm{~kg}, 95.54 \pm 9.48 \mathrm{~kg}, 111.07 \pm 7.56$ $\mathrm{kg}$, compared with the data of domestic yak mentioned above, there had an obvious $(\mathrm{P}<0.05)$ and significant difference $(\mathrm{P}<0.01)$ between two groups except newborn weight.

The body weight of cows in nursing and non-nursing states increased by $3.4 \mathrm{~kg}$ (2.04\%) and $13.65 \mathrm{~kg}$ (7.66\%) in one year respectively, the body weight for nursing cows increased $18.98 \mathrm{~kg}$ from spring to autumn, decreased $15.57 \mathrm{~kg}$ from autumn to the ending of next spring, while the non-nursing cows showed an obvious increase of their body weight from later spring to autumn in 1997, but a rapid decrease from the autumn in 1997 to the next spring in 1998 (Table 2), the daily gain had a significant difference between two groups from May to November in 1997 ( $\mathrm{P}<0.01)$,but no difference in other periods ( $\mathrm{P}>0.05)$. The T-test also showed that the daily gain in nonnursing cows from $\mathrm{T} 1$ to $\mathrm{T} 2$ stage was obvious higher than T2-T3 and T3-T4 stage $(\mathrm{P}<0.05)$; T1-T2 period had significant difference than T2-T3 and T3-T4 periods ( $<<0.01)$, T2-T3 higher than T3-T4 stage $(\mathrm{P}<0.05)$. 
Table 2

Body weight of cows at different nursing states (Körpergewicht der Kühe mit unterschiedlichem Säugestatus)

\begin{tabular}{l|l|l|l|l} 
Nursing state & $\mathbf{1 0}$ May 1997(T1) & $\mathbf{7 ~ N o v . 1 9 9 7 ( T 2 )}$ & $\mathbf{1 5}$ Mar.1998(T3) & 7 June 1998(T4) \\
\hline Nursing & $166.8 \pm 27.5$ & $185.7 \pm 33.2$ & $172.7 \pm 32.2$ & $170.2 \pm 19.2$ \\
Non-nursing & $178.1 \pm 17.5$ & $243.2 \pm 20.6$ & $222.0 \pm 13.3$ & $191.8 \pm 11.7$ \\
\hline
\end{tabular}

The results in Table 3 indicated that all items for the yak over 10 years old had a significant difference with that of 5-7 years old draft $(\mathrm{P}<0.01)$. The live weight, dressed weight, net weight, bone, eye-muscle area for 10 year old were $373.30 \pm 25.20$ $\mathrm{kg}, 210.30 \pm 24.70 \mathrm{~kg}, 176.40 \pm 24.80 \mathrm{~kg}, 33.90 \pm 2.30 \mathrm{~kg}, 53.20 \pm 9.40 \mathrm{~cm}^{2}$, while the above items for $5-7$ years old were $203.30 \pm 27.50 \mathrm{~kg} ; 110.80 \pm 25.50 \mathrm{~kg}, 90.60 \pm$ $35.30 \mathrm{~kg}, 20.10 \pm 7.0 \mathrm{~kg}, 41.40 \pm 10.80 \mathrm{~cm}^{2}$.

Table 3

Meat production of local yak (Fleischerzeugung von domestizierten Yaks unterschiedlichen Alters)

\begin{tabular}{cccccc}
\hline $\begin{array}{c}\text { Age } \\
(\text { year })\end{array}$ & $\begin{array}{c}\text { Live weight } \\
(\mathrm{kg})\end{array}$ & $\begin{array}{c}\text { Dressed weight } \\
(\mathrm{kg})\end{array}$ & $\begin{array}{c}\text { Net meat } \\
(\mathrm{kg})\end{array}$ & $\begin{array}{c}\text { Bone } \\
(\mathrm{kg})\end{array}$ & $\begin{array}{c}\text { Eye muscle area } \\
\left(\mathbf{c m}^{2}\right)\end{array}$ \\
\hline$>10$ & $373.3 \pm 25.2^{* *}$ & $210.3 \pm 24.7^{* *}$ & $176.4 \pm 24.8^{* *}$ & $33.9 \pm 2.3^{* *}$ & $53.2 \pm 9.4^{* *}$ \\
$5-7$ & $203.3 \pm 27.5^{* *}$ & $110.8 \pm 25.5^{* *}$ & $90.6 \pm 25.3^{* *}$ & $20.1 \pm 7.0^{* *}$ & $41.4 \pm 10.8^{* *}$ \\
\hline$* * \mathrm{P}<0.01$ & & & & &
\end{tabular}

The milk productivity in Table 4 showed daily milk are $1.06 \pm 0.16 \mathrm{~kg}, 0.67 \pm 0.09 \mathrm{~kg}$ for multiparous yak and primiparous yak individually, there are obviously difference $(\mathrm{P}<0.05)$, no mater the multiparous yak or the primiparous yak, milk yield was higher in June, July and August than in May and September $(\mathrm{P}<0.05)$, had significant difference for $4 \%$ FCM in the multiparous yak $(1.47 \mathrm{~kg})$ than in the primiparous yak $(0.94 \mathrm{~kg})(\mathrm{P}<0.01)$.Milk fat was $6.57 \pm 0.23 \%$ in multiparous yak and $6.69 \pm 0.15 \%$ in primiparous yak ( $>0.05$, Table 4$)$.

Table 4

Milk production in yak (Milchleistung von Yaks)

\begin{tabular}{|c|c|c|c|c|c|c|c|}
\hline \multirow{2}{*}{ group } & \multirow{2}{*}{ item } & \multicolumn{5}{|c|}{ milk month } & \multirow{2}{*}{ average } \\
\hline & & May & June & July & August & September & \\
\hline \multirow{2}{*}{$\begin{array}{c}\text { Multi- } \\
\text { parous } \\
\text { yak }\end{array}$} & $\begin{array}{c}\text { daily milk } \\
\text { production }(\mathrm{kg})\end{array}$ & $0.75 \pm 0.18$ & $1.49 \pm 0.27$ & $1.30 \pm 0.20$ & $1.13 \pm 0.22$ & $0.63 \pm 0.11$ & $1.06 \pm 0.16$ \\
\hline & $\begin{array}{l}\text { milk fat (\%) } \\
\text { 4\%FCM (kg) }\end{array}$ & $\begin{array}{c}5.92 \pm 0.83 \\
0.97\end{array}$ & $\begin{array}{c}6.56 \pm 0.23 \\
2.06\end{array}$ & $\begin{array}{c}6.77 \pm 0.38 \\
1.84\end{array}$ & $\begin{array}{c}6.62 \pm 0.48 \\
1.57\end{array}$ & $\begin{array}{c}6.98 \pm 0.19 \\
0.91\end{array}$ & $\begin{array}{c}6.57 \pm 0.23 \\
1.47\end{array}$ \\
\hline \multirow{2}{*}{$\begin{array}{c}\text { Primi- } \\
\text { parous } \\
\text { yak }\end{array}$} & $\begin{array}{c}\text { daily milk } \\
\text { production (kg) }\end{array}$ & $0.59 \pm 0.07$ & $0.82 \pm 0.14$ & $0.87 \pm 0.17$ & $0.69 \pm 0.13$ & $0.36 \pm 0.04$ & $0.67 \pm 0.09$ \\
\hline & $\begin{array}{l}\text { milk fat (\%) } \\
4 \% \text { FCM (kg) }\end{array}$ & $\begin{array}{c}6.72 \pm 0.16 \\
0.83\end{array}$ & $\begin{array}{c}5.28 \pm 0.74 \\
0.98\end{array}$ & $\begin{array}{c}7.10 \pm 0.11 \\
1.28\end{array}$ & $\begin{array}{c}7.25 \pm 0.08 \\
1.03\end{array}$ & $\begin{array}{c}7.10 \pm 0.14 \\
0.53\end{array}$ & $\begin{array}{c}6.69 \pm 0.15 \\
0.94\end{array}$ \\
\hline
\end{tabular}

\section{Discussion}

In general, birth weight in yak is low, ranging from $10 \mathrm{~kg}$ to $16 \mathrm{~kg}$ and representing about 3 to 7 percent of adult weight. The relatively low birth weight is a consequence of a relatively short gestation length (average 258 days) and that the fact that in midand late pregnancy the yak ,typically ,has to exist on ground that is frozen and covered with ice and snow. Also, the yak does not normally have the benefit of supplementary feeding. For these nutritional reasons, the physical condition of the female yak is at its lowest in late pregnancy thus leading to nutrient deficiency for the foetus at the very time when the foetus is at its most demanding. The Jiulong yak of Sichuan province 
with the highest absolute birth weights (15.5kg) and this study for Guoluo yak just only $11.74 \pm 1.27 \mathrm{~kg}$ (CAI LI et al., 1980).

The manner in which the yak calf is reared profoundly affects its growth. The three main classes are: 1) to give the calf exclusive access to the milk of its dam (the dam is not milked), 2) to milk the dam once a day and allow the calf the reminder, and 3) to milk the dam twice a day and allow the calf what remains. An additional category (a subdivision of the first class) is that dams that are not milked may a) be allowed to graze at night or b) not be allowed to graze if kept restricted overnight with the yak females that are milked. There are many studies on the effects of these rearing treatments on calf growth. There is generally a beneficial and quite large effect on calf growth when the calf has access to all the milk of its dam. Often, the largest difference is between calves allowed to dams milked only once a day compared with those reared by dams milked twice daily. Normally, the calves are tethered when their dams are milked. When the dam is milked only once daily, the calf is tethered and kept from the dam for a relatively short time only and grazes and drinks water alongside the dam for most of the day. Calves with dams milked twice a day are tethered for much of the day and have perhaps only four to five hours of time during which they move around at pasture with their dams. In a similar study by YANG RONGZHEN et al. (1997), the main difference in growth of calves was between those from dams not milked compared to those milked-with, usually, no effect due to frequency of milking. In this study, calves at age of 18 months weighed around one third less if their dams were milked than if they were not milked. LU GUANGHUI (1980) observed 180 yak steers from birth to five years old found that the weight loss of calves over the first winter was around 12-15 percent of the weight before the onset of winter. Typically, over the following summer and autumn young yak regain their weight losses and may well double in weight before again losing, over the second winter of life, perhaps 25 percent of the maximum weight reached. The cycle of weight gain and weight loss continues throughout life. In fully adult yak, the weight loss in the cold season is roughly equal to the gain in the following warm season. Our study is different from above report, so it is very important to change the milking from twice a day to once a day or no milking in Guoluo area, which will increase the yak performance largely. ZI XIANGDONG et al. (2004) reported that the Jiulong yak grows rapidly to puberty at 2 to 3 years of age, the females reached $143.0 \pm 34.7 \mathrm{~kg}$ and $184.0 \pm 30.8 \mathrm{~kg}$ respectively, which was $60-80 \%$ of their mature weight at 6 to 7 years old, then the rate of growth significantly slowed down, male continued to rapidly increase body weight until an older age possibly due to the selection procedure, the growth regulation in Guoluo yak is similar to Jiulong yak, but the body weight in different stage is largely lower than Jiulong yak for the systematically selection and no milking in Jiulong yak.

One of the important factors influencing milk yield is pasture production-the quantity, growth status and nutritive value of the herbage. These are, in turn, affected by climate and season. All lactating yak, irrespective of age, parity or breed type and even location, tend to peak in July and August when grass is its best in terms of quality and quantity. These months are known in yak-producing areas of China as the "golden age", before July, though the grass has started to turn green and to grow, the amount of grass available is not high. After August, as air temperature falls, the nutritive value declines-as the grass produces seeds and then wilts, and the content of crude fibre of the grass is high. LONG RUIJUN (1994) reported that yak milking twice daily was 
carried out in Gannan region, Southern Gansu and Haibei region, Northern Qinghai, with an average milk yield of $1.22 \pm 0.26 \mathrm{~kg}$ and $1.26 \pm 0.31 \mathrm{~kg}$. SAKAR et al. (2000) studied the milk yield using 7 multiparous yaks found that milk yield varied from 0.45 to $3.25 \mathrm{~kg} /$ animal/day, yield increased from the start of lactation to a peak at 12 weeks after parturition, where it remained constant for 4-5 weeks, then declined to the end of lactation. Our research is similar to above report.

Wild yaks (Bos mutus) are very precious animal resources, and fully protected under Chinese wildlife protection legislation. Recent reports associated with the study of distribution, status and ecology of wild yak and main problem of wild yak in China PU RENZHU et al. (1999) and PEN XIANWEN and OU (1999) show that there are between 15,000-20,000 wild yaks distributed in 5 isolated regions comprising about $466.000 \mathrm{~km}^{2}$. Both wild yak and domestic yak belong to the same genus but to different sub-species. Wild yaks have stronger adaptability to cold, shortage of forage and variable weather. Making use of wild yak may rejuvenate and improve the production of domestic yak. There were quite a lot of research work in this field (JIAO XIAOLU and YAN SHOUDONG, 2004; CHEN ZHENGRONG; JI QUIMEI et al., 2004), our study further proved that the body weight of $1 / 4$ wild yak had an obvious or significant difference compared with domestic yak.

In a trial in Sichuan province, entire male yak from the age of 1.5-4.5 years and thereafter, yak steers to the age of 20.5 years were chosen at random from yak herds in the same area and kept under year-round grazing without supplementary feeding. All the animals were slaughtered at the end of autumn, in their fattest condition. The trends showed that the dressing percentage increased with age (and live weight) up to six and a half years and declined somewhat thereafter (ZHONG GUANGHUIet al., 1993). ZI XIANGDONG et al. (2004) using 20 males aged from 2.5 to 6.5 years, seven females aged of 4.5 years and 11 steers aged 4.5-5.5 years were slaughtered for carcass determination. Dressing percentage and ribeye area ranged from 48.53-55.04\% and $48.02-68.56 \mathrm{~cm}^{2}$, both of which differed by age and sex. The dressing percentage in our study for 5-7 years and over 10 years draft were $56.3 \%$ and $54.5 \%$ respectively, the dressing percentage had no difference but ribeye was lower than above report.

\section{Acknowledgements}

The authors are most grateful to the financial support from the Project Office of Qinghai Animal Husbandry Bureau.

\section{References}

CAI, L.; XIAO, Z.Q.; ZHANG, J.Z.; WANG, T.H.:

The good meat-purpose yak-the investigation and study of Jiulong Yak. Journal of China Yak 1 (1980), 14-33

CAI, L.;WIENER, G.; HANG, J.L.; LONG, R.J.:

The Yak. RAP Publication, Regional Office for Asian and the Pacific of FAO, Bangkok, Thailand. 2003

CHEN, Z.R.; JI, Q.M.; DAWA,Y. L.:

Advances on research on yak production system in China. Proceedings of the fourth international congress on yak (2004), 47-56

JIAO, X.L.; YAN, S.D.:

Research on comprehensive techniques for yak improvement. Proceedings of the fourth international congress on yak (2004), 63-70

LONG, R.J.:

Milk performance of Yak cows under traditional feeding and management on small Tibetan farms. Acta 
LU, G.H.:

Prataculturae Sinica 3 (1994), 71-76

The regulation of change of yak's body weight and relationship between its slaughtered age and different seasons under the condition of natural grazing. Abstract Collection of Thesis of Animal LUO, X.L.: Husbandry and Veterinary Medicine of China (1980), 26

Extending and Utilizing of Wild Yak Semen in Yak Raising Areas. Arch. Tierz., Dummerstorf 44 (2001) Special Issue, 138-140

PEN, X.W.; OU, Y.X.:

Ecological adaptability of wild yak. Journal of livestock ecology 20 (1999), 20-23

PU, R.Z. ; MA, Y.Q. ; CUI, H.S. :

Study on the situation of Chinese wild yak. Journal of life science research 3 (1999), 161-169

SARKAR, M.; BASU, A.; DAS, B.C.; DAS, D.N.; MONDAL, D.B.:

Lactation curves of milk yield and some major milk constituents of yak. Indian Veterinary Journal $\mathbf{7 7}$ (2000), 551-552

YAN, S.D.:

A study on the improvement of yak reproductive performance by introducing wild yak blood. Proceedings of the third international congress on yak (2002), 324-327

YANG, R.Z.; LUO, X.L.; LI, Q.; XU, J.T.; WU, K.X.; WEI, Y.P.:

Report on growth and development of domestic yak progenies rejuvenated by wild yak. Proceedings of the second international congress on yak (1997), 21-23

ZHONG, G.H.; ZI, X.D.; CAI, L.;QI, G.Y.;ZHU, H.J.;LIU, C.L.;NI, Y.A.;YEZI, Y.H.;ASHI, M.G.:

Study on meat performance of Jiulong yak. Journal of China Yak 4 (1993), 12-15

ZI, X.D.; ZHONG, G.H.; WEN, Y.L.; ZHONG, J.C.; LIU, C.L.; NI, Y.A.;YEZI, Y.H.; ASHI, M.G.:

Growth performance, carcass composition and meat quality of Jiulong yak (Bos grunniens). AsianAustralasian Journal of Animal Science 17 (2004), 410-414

Received: 2005-03-03

Accepted: 2005-11-03

Authors' Addresses

Prof. LUO XIAO-LIN*, ZHAO XIN-QUAN

Northwest Institute of Plateau Biology,

China Academy of Sciences,

Xining, 810003, P.R.China

* Corresponding author

E-mail: luoxl2004@sina.com

XU JINGTAO, LI QUAN, WEI YAPING

Qinghai Academy of Animal and Veterinary Sciences,

Xining, 810003, P.R.China 